\title{
LA LÓGICA POÉTICA. UNA FENOMENOLOGÍA DEL PENSAMIENTO ARTÍsTICO.
}

\section{The poetical logic. A phenomenology of artistic thought}

\author{
JoAquín SÁNCHEZ-RuIZ \\ Profesor titular Departamento Escultura. Universidad de Granada. \\ joaquinj@ugr.es \\ Pedro Chacón
}

Becario Investigación F.P.U. Departamento Didáctica de la expresión musical, plástica y corporal.

Universidad de Granada.

pchacon@ugr.es

NACHO BELDA

Becario Investigación F.P.U. Departamento Dibujo. Universidad de Granada. nachobelda@ugr.es

Recibido: 4 de Mayo de 2010

Aprobado: 14 de Julio de 2010

\section{Resumen:}

Tratamos de ampliar la noción de verdad, desde el terreno racional hacia el subjetivo. No sólo existimos desde el pensar, sino desde el sentir. Si aplicamos el método cientí f co a todo, nos quedamos sin arte. Reclamamos adherirnos a la vivencia íntima de lo subjetivo. En arte, el ojo introduce la perspectiva, eliminando el mar gen de interpretación. Con la materia ocurre algo similar: verbo es a materia como forma es a nombre. La academia ha dado importancia a la forma, olvidándose de las cualidades poéticas de la materia; ha enfocado la f gura y se ha olvidado del fondo. Sin embar go, hemos de estar atentos a lo accidental, a la ruptura del protocolo, al vértigo de lo vivo. Para ello, prestamos atención a nuestra intuición, al subsuelo dormido de nuestra experiencia ordinaria, cuya mecánica ha terminado perdiendo el valor disruptivo de la acción. Este artículo termina ofreciendo ejercicios prácticos que persiguen revitalizar nuestros centros de atención.

Palabras clave: Lógica poética, imaginación, palabras, materias, onirismo.

Sánchez-Ruiz, J. Chacón, P. Belda, N. 201 1: La lógica poética. Una fenomenología del pensamiento artístico. Arte, Individuo y Sociedad, 23 (1), 9-18.

\begin{abstract}
:
We tried to extend the notion of truth, from the rational concept towards the subjective one.We not only exist by the thought, but also by the feeling. If we apply the scientif $\mathrm{c}$ method to everything, we remain without art. We want to adhere ourselves to the intimate experience of the subjective thing. In art, the eye introduces the perspective and eliminates the interpretation possibility. Something similar happens with the matter: verb is to matter as name is to form. The Academy has given importance to the form,
\end{abstract}


and it has forgotten the poetical qualities of the matter; it has focused on the f gure and it has forgotten the background. However, we have to pay attention to the accidental thing, to the rupture of the protocol, to the frenzy of everything that is alive. For this reason, we pay attention to our intuition, to the sleepy subsoil of our ordinary experience whose inertia has lost the disruptive value of the actionAt the end of this article we offer practical exercises, with which we wish to revitalize our centres of attention.

Key words : Poetical logic, imagination, words, matters, onirism.

Sumario: 1.- Verdad científ ca y verdad experiencial. 2.- El sustantivo, el verbo y el gerundio 3.- Palabras como energía y como objeto 4.- Materias y formas 5.- Imaginando: experiencias oníricas. 6.- Referencias bibliográf cas.

\section{1.- Verdad científica y verdad experiencial}

La prueba más íntima de la existencia del agua es la sed. Heinz von Föster

Un kilo de plomo pesa más que un kilo de plumas. Un niño cualquiera.

Pierde tu mente, recobra tus sentidos. F. Perls

Para Brunner (1988), nuestra forma de pensar condiciona al mundo. No todos pensamos ni sentimos de la misma manera. Solemos cometer dos errores: creemos que todos ref exionamos igual y que siempre se ha hecho de semejante forma. Pero lejos de ser así, el cerebro es tan plástico, que pone a nuestra disposición una inmensa paleta de formas de pensar: literalmente cada persona es un mundo. A través de las diferentes estrategias de con-jugar la mente (oral, abstracta, alfabética, etc.) cada cultura preestablece y promociona un tipo de pensamiento y rechaza otros. Como en Occidente utilizamos sobre todo la parte más reciente del cerebro, no sólo lo tomamos como un proceso superior de conciencia ( f g.1). Así, estamos persuadidos que esto nos convierte en humanos (homo sapiens, sapiens) despreciando el resto de nuestras funciones vitales. Sin embargo, toda relación cultural con el mundo resulta convencional. Por otra parte, nuestro cuerpo está preparado para participar totalmente con el exterior. Estamos llenos de agujeros y somos como membranas: tocamos y somos tocados, vemos y somos vistos. El mundo se moldea con nuestra propia carne dispuesta a expresarse.

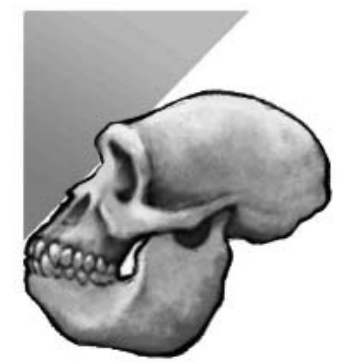

Fig.1 La frente se abate adelante con el desarrollo cerebral. Esta adquisición reciente no es la única que nos vuelve seres humanos. Ilustración de Nacho Belda. 
Lo objetivo se considera un logro per se, aunque tenga una nula repercusión en nuestro bienestar emocional. Actualmente hemos sido adiestrados a descon $\mathrm{f}$ ar de los sentimientos y se nos obliga a razonar sobre sus consecuencias, para encontrarles una lógica de las que tal vez carezcan. Parece arbitrario que la objetividad obtenga el marchamo científ co de verdad y que a través de la subjetividad se nos niegue arribar a la certeza. Sólo la experiencia directa nos devuelve la frescura y creatividad, al restituir nuestro dominio sobre una parte hipertrof ada -el pensamiento racional- que ha tomado el mando, arrinconando gran parte de nosotros. El artista incorpora a la cabeza pensante el cuerpo sintiente, pues una cabeza a secas no vivirá mejor que un cuerpo sin cabeza (fg.2).

\begin{tabular}{|ll|}
\hline \multicolumn{1}{|c|}{ Ego } & \multicolumn{1}{c|}{ Cuerpo } \\
Consciencia & Respuesta involuntaria \\
Logro & Placer \\
Pensamiento & Sentimiento (respuesta espontánea al medio) \\
Adulto & Niño \\
Individualidad & Comunidad (comunicación) \\
Cultura & Naturaleza \\
\hline
\end{tabular}

Fig.2 Representación de los extremos entre el yo racional y el yo corpóreo.

Las proposiciones pueden ser objetivas (ciencia) o subjetivas (arte). Lo objetivo no desemboca siempre en lo verdadero y la verdad participa también de lo subjetivo. Ambos, lo racional y lo emotivo, elaboran universos igualmente basados en especulaciones, que conf guran una visión del mundo. Para Goodman (1990) no podemos aplicar la falsación de Popper en un cuento. Las fórmulas matemáticas se han blindado ante cualquier interpretación, pero aplicando el método cientí f co nos quedaríamos sin novelas, sin teatro, ni poesía. Tan diversos son los patrones como los resultados. El lenguaje es una síntesis entre el yo y el mundo, a partir de una reproducción de lo externo y de la expresión de lo interno. Para hacernos una idea, ciencia es a casa como arte es ahabitarla. Los argumentos lógicos convencen así por su verdad, en tanto que los relatos oníricos nos atrapan por su semejanza con la vida. El silogismo $\mathrm{A}=\mathrm{A}$ es transgredido para crear perspectivas múltiples. Nosotros como artistas creemos verosímil que un kilo de plomo pese más que un kilo de plumas y nuestro convencimiento se ancla en la densidad y peso poético de esas materias. En arte sentimos lo inmediato, que se adhiere a los acontecimientos de manera no menos precisa. Más que un discurso ilativo, el arte se compone de esfuerzos para quedarse en los sentimientos de una manera completa y total, sin separar la campana de su sonido, ni éste del campanero. Gozamos de esa compenetración, donde observante y observado coinciden. 


\section{2.- El sustantivo, el verbo y el gerundivo. (Donde lo objetivo es sustantivo masculino y lo subjetivo es verbo conjugable).}

Que son las cosas quienes nos tienen y no nosotros a ellas,que es el ser el que habla dentro de nosotros y no quienes hablamos del ser.

Gastón Bachelard

Desde el racionalismo se ha pensado una realidad de objetos separados entre sí. Sin embargo, sólo al experimentar las cosas, al con-jugar-las, nos completamos. No existe la objetividad, ni siquiera la subjetividad, sino la trans- o inter -subjetividad. Poseemos habilidades artísticas, racionales, musicales, abstractas, orales, alfabéticas, etc. Cada una de las cuales se puede activar a partir de palabras escritas, habladas, imágenes concretas o fantasía y esto depende de cómo movamos nuestra mente. La reordenación de nuestros sentidos, en una dirección u otra, proporciona diferentes ángulos de un mismo acontecimiento. Cuando se promociona un sentido se anestesian otros. Ese es el principio de la hipnosis según Grinder y Bandler (1997), acallando unos mediante la desproporción. De hecho, el hombre tribal arcaico, que vivía intensamente el sonido, podría pasar como un ser en trance constante para los alfabetizados actuales... y viceversa.

En lo femenino el verbo dirige la realidad. Al principio era el verbo, el motor de la vida, era diosa, aunque Tomás de Aquino se apresuró a puntualizar: In generatione verbi Dei non competit ratio matris, sed solum patris (en Luciani Rivero 2002), algo así como una fecundación sin participación femenina. De Hermes se deriva hermeneusis, la explicación de las cosas. La intuición y comprensión femeninas se enfrentan a la racionalidad y explicación viril. Hermes se asienta en el límite, la frontera masculino-femenina (herm-afrodita). La madre ambivalente de vida y muerte, pasará al cristianismo como origen del pecado, de la disolución pre-lógica. Recordemos en este punto un poco de gramática latina. Todos sabemos que el verbo posee los modos de in f nitivo (relacionado con el sustantivo), gerundio (en relación al adverbio) y participio (en relación con el adjetivo). El latín posee además el gerundivo. Así llegan en castellano amante, sintiente, pensante, etc. El actuante es el actor en la acción, de manera que no se queda en la mera presencia, sino que participa y se funde en ella; ha de llevarlo a cabo. Aunque de la misma raíz, la palabra fideicomisario se aísla def nitivamente de los acontecimientos, mientras que la palabra fehacie-nte se vincula a ellos; es más, sin ellos carece de existencia inherente. ¿Podríamos rescatar el gerundivo para el arte? ¿No seríamos nosotros los artistas en puridad pinta-ntes, esculpie-ntes o comunica-ntes, a la manera de (otro gerundivo) los estudia-ntes?

En la palabra género, genus, se aúnan útero y tumba ( $\mathrm{fg.3}$ ). Del summun genus de la diosa madre, del sexo generador de todo, se pasa al ens supremun, el ente def nidor, delimitador de las cosas, creador por nombrarlas. En lo masculino el nombre constituye lo sustantivo, mientras que del verbo nace el juego de dar y tomar para comprender el mundo. El verbo es experiencial, necesita consenso, reconciliación frente al sustantivo. Aristóteles concede importancia al nombre sobre el verbo, que se ve acotado y determinado. El sustantivo sólo es capaz de captar lo mensurable. De Lux se inf ere logos y logos dará en alemán Lügen (¡que signif ca mentir!). Para com- 
prender (asir, palpar) lo alógico se ha de hacer un esfuerzoilegítimo: usar un lenguaje materno, plural, frente al lenguaje a flado paterno. Las signi f caciones modelan las palabras mediante su uso y éstas no reciben objetivamente a aquéllas, aunque el positivismo lógico se empecine en tratarlas como un sistema de signos que copiarán f elment la realidad.En la f losofía de Humboldt el lenguaje signif ca sobre todo actividad, pues se engendra a sí mismo perpetuamente y es un don que se recibe haciendo uso de él. Ha de expresar el palpitar de cada ser y laslesviaciones de la norma habría que calif carlas como perpetua mutación. El objeto consiste en el suceso como experiencia. El suceso convierte al individuo en un instante de un entramado, en la nota de una sinfonía. El ser no es nada sin el devenir.

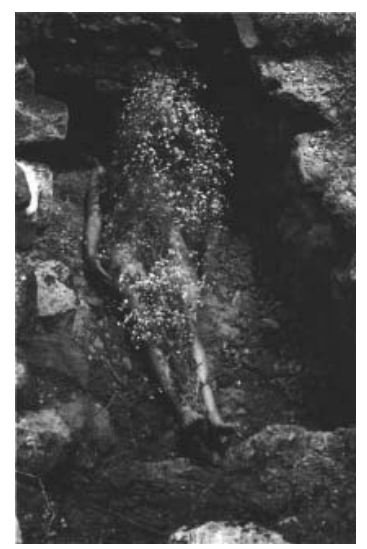

Fig.3 Performance de la artista Ana Mendieta (1985) a partir de su fascinación por la sangre, la muerte y los límites. Mucho tiempo antes, Rilke lo expresó así: Las cosas del arte son, en realidad, siempre cosas del estar en peligro, del haber llegado hasta el límite de una experiencia, allí donde ningún humano puede continuar. Ana terminó su vida defenestrándose por una ventana.

\section{3.- Palabras como energía y como objeto.}

El lenguaje es autorreferente, es decir , para de f nirlo hay que emplearlo. Además es profundamente carnal, pues el cuerpo habla al unísono y el lenguaje se vuelve afectivo. Los signos se separan de la experiencia directa, hasta cobrar vida propia. Se toman como lo objetivamente real, si bien es un mundo virtual paralelo, creado por convención. Con los seres humanos nos comunicamos cotidianamente con la palabra. Este sonido portador de signif cado poderoso, divino, incluso mágico, afecta a alguien durante años o por toda su vida. Si la esencia del lenguaje oral es inmediata, la del lenguaje escrito proviene de la necesidad de fjar la comunicación en la materia: del gesto o sonido comunicante se ha pasado a la piedra, al papel o al bit comunicante. Originariamente, leer pictografías era similar a comentar un cuadro, de márgenes imprecisos. Su lectura proporcionaba una auténtica audacia interpretativa, como ocurre en el arte. Posteriormente, la escritura fónica se independizó absolutamente de lo representado, volviéndose impermeable a los desconocedores de los sig- 
nos empleados. Con todo, el alfabeto lo constituían al principio sólo lason-sonantes. La palabra sagrada, la que todos pronunciamos secreta e incesantemente era dios: $Y H-W H$ (Yahvé), en el constante ciclo de inspiración y expiración, que nos liga a lo absoluto en cada momento.Así, los sufíes af rman que dentro llevan a dios o que ellos mismos lo son. Con la palabra escrita nos desvinculamos de la experiencia: podemos situarnos a mucho tiempo y espacio de un suceso, estableciendo una frontera entre percepción y lenguaje. Nos aislamos de nuestras raíces sensoriales, (comenzando por el aire-hablado) y perdemos el contacto con los demás seres y con la misma tierra viva del paisaje que envolvió los hechos. ParaAbram (2000) nuestro lenguaje resulta sólo un dialecto del común a todos los seres. El paisaje está vivo y resulta tanto el papel como la escritura. No es mera poesía que el arroyo murmure o que el pájaro cante, pues todos los seres son comunicantes. El lenguaje más-que-humano se establece en un territorio y participan de aquél todos los que lo habitan. Cada lugar tiene sus propios seres y por tanto resulta único y tiene su propia alma. En el espacio vivido solo hay lugar para la experiencia, sin distinción de lugar o tiempo: es aquí y ahora, es presente. Hoy el territorio se reduce a mero solar , por eso nos sentimos únicos, en una tierra inerte. Nos hablamos sólo a nosotros mismos y ya no más a las plantas o a los animales. La tragedia de la extinción de otros seres vivos radica en que ya no podremos aprender de su sabiduría.

Aunque nada ha habido tan fundamental en el progreso de la cultura como la palabra escrita, se ha evaluado muy poco su coste: la aniquilación de lo femenino, según Shlain (2000). La visión femenina es holística, simultánea y concreta. Lo masculino se limita a lo secuencial y abstracto. Si el medio es el lenguaje, según Mc Luhan (1998), una persona alfabetizada no piensa como otra de tradición oral. Actualmente pensamos tanto en imágenes como en discurso verbal lineal y secuencial. Baste callar por un minuto y aparecerán unas y otras en catarata. Lamentablemente, la cacofonía del ruido inter f ere en la comunicación. De un escenario natural donde los sonidos son lo más importante (el bosque o la oscuridad), hemos pasado a otro (la ciudad) donde hay que aprender a ignorarlos. De la palabra resonante, repleta de elementos dramáticos, pasamos a un orden visual car gado de objetos explícitos y ordenados. Los analfabetos (palabra empleada como insulto) sienten el mundo como un mosaico y en profundidad auditiva, con unas relaciones hoy inimaginables. La audición es cosmocéntrica, en tanto que la visión es logocéntrica. Los cetáceos se basan en un matriarcado auditivo, en tanto que las águilas visuales capturan sus piezas como nosotros captamos conceptos. La palabra escrita pasa del dinamismo al estatismo. El sentido de la vista es obsesivo y exclusivo. La imprenta eliminó el sonido de la palabra hablada y la trató como un objeto. Igualmente la perspectiva euclidiana propuso un espacio entendido como receptáculo neutro de las cosas. Los pintores arcaicos representaban frecuentemente la imagen en distintas escenas, considerando que así se completaban las relaciones espacio-temporales. En el Renacimiento, la perspectiva $\mathrm{f}$ ja el cuadro como si fuese un fotograma (f gs.4 y 5 ). 

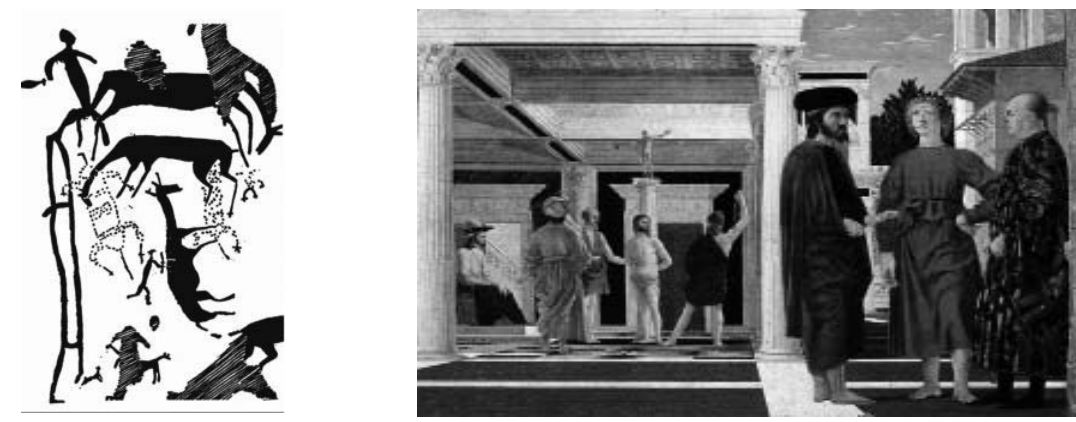

Fig.4 (izquierda): pintura rupestre de la cueva de Toquepala (Perú). En la profundidad de la caverna se representa el olor y sonido, el miedo, la velocidad, el acecho, los gritos de euforia... todo tiene cabida en el juego de la representación.Figura 5 (derecha): perspectiva clásica de Piero della Francesca: el receptáculo neutro como teatro de representación. La visión unidireccional (punto de fuga) ha ganado la partida.

\section{4.- Materias y formas. (Donde la materia significa posibilidad de lo difuso e inexacto).}

La materia es informe y caótica. Por ello la forma se ha promocionado sobre ella. Para Aristóteles, la forma es masculina y la materia femenina. La dualidad terminó extendiéndose a los siguientes pares contrarios: real/posible, alma/cuerpo, divino/ profano, mejor/peor, etc. Lo inferior se relega a la materia y el espíritu se considera como el actuante, frente al alma sensual. Un dios varón es la consecuencia cristiana de lo dicho, aunque para Eckhardt dios sea padre y madre y para Scheler (1961) las culturas más ricas nazcan de un estado bipolar . La Gestalt analiza las formas y sus desviaciones particulares. Esta teoría predecía que a los ciegos que recuperasen la vista les sería fácil emer ger al mundo de los videntes. No fue así, pues no captaban la complejidad de manchas de colores, luces y movimiento, que les hacían perderse en el terror de lo nuevo. Percibimos más que formas y sobrevivimos caricaturizando, no clasi $f$ cando, cualquier elemento en una totalidad borrosa, de la que vamos comprendiendo cada vez con mayor de f nición. La Gestalt distingue f gura y fondo, lo signif cante y lo que no lo es. Pero para el artista, el fondo entendido como lo no evidente se revela tan poderoso como la f gura. Lo subliminal no es ni débil, ni mucho menos anodino. Mientras la visión super $\mathrm{f}$ cial tiende a la disyuntiva: o esto o lo otro; la captación profunda conduce a lo holístico. Contrariamente al artesano y al académico, a los que se les alaba por el control en el proceso, el artista actúa mediante otro tipo de comprensión. Es así como aprende de forma indeleble el niño. A él no le parece urgente captar de una sola vez el signf cado completo de una palabra: disfruta jugando a distorsionarla o inventa otras nuevas. La enseñanza académica del arte premia la ejecución certera, de contorno duro, frente a la atmosférica y vaga. Lo difuso se evita como horror al caos disolutorio, pero Nietsche (2007) advierte:Alles Gerade lügt, todo lo preciso miente. La intuición creativa brinca por lo provisional hacia lo def nitivo, moviéndose a través de una estructura incompleta. Incluso cree ventajoso 
que un motivo inicial no cristalice prematuramente en unabuena forma, desplegando la obra orgánicamente, imposible de predecir qué será al momento siguiente. El tér mino accidente aquí resulta revelador.

En un principio fue el caos, dijo Hesíodo en suTeogonía (1910), lo que supone un tiempo sucesivo previo a la razón discursiva. En el Tao Te Ching (1994) se lee que sigue estando presente en las cosas. La acepción de kháos no signif ca desorden sino la abertura del abismo, más parecido a un descomunal bostezo cósmico. Abertura que equivale a posibilidad creativa. La inteligencia ordinaria se adecua a lo real, es estática y a posteriori, mientras que la inteligencia intuitiva se inserta en lo real, en simbiosis con la durée, con el tiempo presente. Bergson (1985) af rma que la verdad es la convivencia con lo real. La intuición nos pone en contacto con la razón de ser , que usualmente cae fuera de nuestro espectro ordinario. El misticismo se basa en la intuición, no en el intelecto. Físicos como Zukav o premios Nobel como Wigner emplean sin reservas la intuición. Ha quedado como una frase recurrente la del matemático K.F. Gauss, cuando escribió: He tenido mis soluciones durante mucho tiempo, pero no sé aún cómo llegar a ellas. Todos sabemos más que la información que se nos ofrece, de forma inexplicable. Dado que lo real es un modelo y que el mundo es algo pensado, al desmontarse desde la Postmodernidad tal consenso sobre lo real, según Maillard (1998) tenemos/podemos construirlo. Mientras que la razón ilustrada lo rememora, la lógica poética es un proceso de estar siendo, es la construcción de mundos posibles, de formas actuantes. Una forma actuante se transmite, modif ca la visión y forma cultura. Si esto en principio parece crear individuos relativistas, curiosamente el poeta cuando habla de sí mismo universaliza, pasando del yo al nosotros.

Cassirer (1982) escribe: Cada uno de los grandes líricos (...) proponiéndose tan solo expresar su propio yo, nos enseña a sentir en realidad el mundo de un modo nuevo.

La obra de arte es el manantial del subsuelo de nuestras experiencias. Va más allá del mero requerimiento animal. Nos transformamos desde dentro y si esto no se logra, es arte inútil. Para Marina Abramovic (2008) Kunst ohne Ethik ist Kosmetik, arte sin ética es cosmética. La imagen artística se dispersa como un perfume y tiene repercusión cuando cambia nuestro ser . El artista puede ser muchas cosas, pero con seguridad no es un positivista lógico. Dice más de lo que el ojo ve, el oído oye o la mente conoce. Entonces la imagen se vuelve productora, no reproductora de Naturaleza. La imagen poética surge de la imaginación, del corazón. Incide en otras almas aún sin preparación cultural, es pues transubjetiva. El pensamiento artístico no necesita saber nada, no endurece ni simplif ca ningún conocimiento, es holístico y no secuencial. La activación nos capta enteros y nos incita a pensar: esto lo he podido hacer yo, porque lo siento igual. Así, el espectador se vuelve un cocreador , no un crítico, pues toda crítica destruye la imagen. El verdadero arte resulta imprevisible y lo imprevisto se vuelve un gran fastidio para la explicación racional. El arte no es un lenguaje que sea bueno forzar hasta la precisión, más bien se le debe proveer de brumas que eviten convertirlo en un instrumento de conocimiento exacto.Así, resulta un contrasentido estudiar objetivamente la imagen. Bachelard (1986) señaló la paradoja de que una buena lectura obliga a cerrar el libro: 


\begin{abstract}
Queremos siempre que la imaginación sea la facultad de formar imágenes. Y es más bien la facultad de deformar las imágenes (...) Si no hay cambio de imágenes, unión inesperada de imágenes, no hay imaginación, no hay acción imaginante. (...) Si una imagen ocasional no determina una provisión de imágenes aberrantes, una explosión de imágenes, no hay imaginación (...) El valor de una imagen se mide por la extensión de su aureola imaginaria (...) Como proclama Blake : La imaginación no es un estado, es la propia existencia humana.
\end{abstract}

Esta lógica poética consiste en la dislocación, rompiendo estereotipos y devolviéndonos a nuestro estado de frescor La fórmula que ofrece Guillaumin (1981) consiste en hacer estallar el discurso: obras plenas para una vida plena. El arte se sitúa al límite de lo decible/indecible. De ahí que, como prevé LaoTse (1994), el verdaderamente sabio termine por callar. El lenguaje recupera su capacidad inter -subjetiva conjugando el verbo; lenguaje por lo demás análogo, pre-cientí f co, como dicción de lo indecible. Para Merleau-Ponty (1994) la realidad consiste en una experiencia simultánea, total y sensual. La realidad es más que su descripción, es ofrecimiento. Lo alógico puede aprehender la vida con más fuerza que lo lógico si se femeniza, sin actitudes vicarias que pretendan sustituir el hecho por el nombre. Antes que ver y nombrar, hemos de disolvernos en la experiencia dialógica. De lograrse se comprendería el sentido de arte=vida, donde la obra misma pasa a segundo plano. El arte posee un orden oculto en palabras de Ehrenzweig (1973), un substrato polifónico, no una línea unívoca de pensamiento. El pensador consciente se encuentra muy enfocado, en tanto que el pensador creativo f uye por lo indiferenciado, pareciendo incluso caótico. La creación se produce en diversos niveles: con el más profundo, el oceánico, sentimos cómo la personalidad se disuelve en el cosmos, algo ya estudiado en el mandala y el arquetipo del niño creador de Jung. La fantasía inconsciente no sabe de tiempo y espacio.

Hemos tratado en estas líneas de aproximarnos a la dialéctica entre intuición y raciocinio. Elegimos comprender el mundo a partir de Alicia, del sueño y del espejo. ¿Cómo se pueden establecer diferencias entre sensible e inteligible, entre lo intelectual y lo sensitivo? Abandonando lo que se ve y se sabe, a favor de lo que se imagina, eliminando lo aprendido, lo vigilado y lo tutelado. El artista piensa de esta manera y no en conceptos. Frente al historiador que analiza, el artista ensueña y actúa, reemplazando crítica por admiración. El arte no es un silogismo, ni una metáfora, ni una prueba empírica. Dice lo que de otra forma no podríamos contar. Lo esencial de una obra es la intención que la anima, empleando un pensamiento arcaico y pueril. El pensamiento artístico supone activar la imaginación inconsciente y la intuición. Esa es nuestra lógica poética.

\title{
5.- Referencias bibliográficas.
}

Abram, D. 2000: La magia de los sentidos. Barcelona, Kairós.

Abramovic, M. 2008: Performance en Colonia, Museum Ludwig.

Bachelard, G. 1986: La poética de la ensoñación. México, Fondo de Cultura Económica. 
Bergson, H. 1985: La evolución creadora. Madrid, Espasa Calpe.

Brunner, J. 1988: Realidad mental y mundos posibles: los actos de la imaginación que dan sentido a la experiencia. Barcelona, Gedisa.

Cassirer, E. 1982: Las ciencias de la cultura. México, Fondo de Cultura Económica. Ehrenzweig, A. 1973: El orden oculto del arte. Barcelona, Labor.

Elíade, M. 1995: El vuelo mágico. Madrid, Siruela.

Goodman, N. 1990: Maneras de hacer mundos. Madrid, Visor.

Grinder, J. y Bandler, R. 1997:Trance-fórmate. Madrid, Gaia.

Guillaumin, J. 1981: Los sueños y el yo. Barcelona, Paidós.

Hesíodo 1910: Teogonía. Barcelona, La Académica.

Hobson, A. 1994: El cerebro soñador. México, Fondo de Cultura Económica.

Lao Tse 1994: Tao Te King. Málaga, Sirio.

Luciani Rivero, R. 2002: El misterio de la diferencia. Roma, Editrice Ponti f cia Universidad Gregoriana.

Maillard, C. 1998: La razón estética. Buenos Aires, Laertes.

Mc Luhan, M. 1998: La galaxia Gutenber. Barcelona, Círculo de lectores.

Merleau Ponty, M. 1994: Fenomenología de la percepción. Barcelona, Península.

Nietzsche, F. 2007: Also sprach Zarathustra. Wiesbaden, Manesse.

Osho. 1995: Meditación, la primera y última libertad. Madrid, Gaia.

Scheller, M. 1961: El santo, el genio, el héroe. Buenos Aires, Nova.

Shlain, L. 2000: El alfabeto contra la diosa. Madrid, Debate.

Sánchez-Ruiz, J. 2008: Métodos psicológicos y validación de instrumentos de medida en la enseñanza de las Bellas Artes. En II Congreso Internacional de Educación artística y visual, Universidad de Granada. Edición digital. 